\title{
Changes in the death probability of China's elderly population and rethinking the definition of old age
}

\author{
Min $\mathrm{Lu}^{1} \cdot$ Xizhe Peng ${ }^{2} \cdot$ Mengxue Chen ${ }^{3}$
}

Received: 18 April 2018 / Accepted: 10 August 2018 / Published online: 22 August 2018

(c) Springer Nature Singapore Pte Ltd. 2018

\begin{abstract}
A study of the age-specific death probability of China's elderly population from 1982 to 2010 shows that, during the past 30 years, the death probability of China's elderly population has decreased over time. This indicates that the health status of and meaning of age for the elderly population has been changing. At the same time, changes in economic, social and environmental factors and the development of science and technology have not only greatly changed the lifestyles and work situation of the elderly population, but also provided them with more opportunities to participate in economic and social activities, thus making today's elderly people "healthier" and "younger" than those of previous generations. In conclusion, the findings of this paper suggest that it is necessary to rethink the traditional definition of elderly population. In addition, changes in the death probability of the elderly population of China also show significant gender and regional differences domestically, and there are gaps in the death probability of the elderly in China versus in developed countries, indicating that China still has a long way to go to complete a fundamental transformation of death patterns. A full understanding of such changes and differences will allow us to redefine old age and develop a new understanding of the aging society. Such an understanding can also help us to reconstruct the public policy system to meet the needs of a future society in which aging is the normal state of affairs.
\end{abstract}

Keywords Elderly population $\cdot$ Death probability $\cdot$ Definition of age $\cdot$ Aging

This paper is a phase result of the major project of the National Natural Science Foundation of China (NSFC), "Study on Basic and Scientific Issues of Aging Society" (71490735).

Min Lu

lumin@fudan.edu.cn

1 State Innovative Institute for Public Management and Public Policy Studies, Fudan University, 220 Handan Road, Shanghai 200433, People's Republic of China

2 Center for Population and Development Policy Studies, Fudan University, Shanghai, People's Republic of China

3 College of Arts and Social Science, Australian National University, Canberra, Australia 


\section{Introduction}

Global population and social development trends for more than half a century make clear that, compared to previous cohorts of the same age, cohorts today, especially elderly populations, normally have better physical and mental health, accumulate more human and social capital, and also enjoy more rights and opportunities to participate in economic and social activities. The overall population and especially the elderly population have undergone significant changes. Because the socioeconomic background and the technological environment are also changing, today's elderly population is different than the elderly of previous generations. However, the traditional definition of "old age" has remained unchanged for a long time, and this means that simple physiological age standards actually ignore the changes in psychological age and social age. The traditional definition has become increasingly ineffectual at reflecting real world population dynamics, and thus distorts our understanding of the aging population and limits our ability to develop strategies to cope with aging. Redefining "old age" and "aging" will enable us to have a new understanding of the aging society, and thus help us to reform and reconstruct the social policy system in a future society in which aging is the normal state of affairs, so as to effectively cope with the challenges brought by an aging population. There are many perspectives from which to discuss the changes to demographic development trends. This paper looks at the change of death probability of the elderly population as a means to discuss how to redefine "elderly" and deal with the challenge of population aging.

\section{Rethinking old age against the backdrop of population aging}

\subsection{Population aging is the new normal for Chinese society in this century}

Population aging is the result of decreases in both fertility rates and mortality rates. Population migration also affects the aging process. With the continuous development of the social economy, and the continuous advance of industrialization and urbanization, the level of public health and social security has gradually improved, and the life expectancy of the population has steadily increased. Fertility intentions and actual fertility behaviors both serve to move fertility to a lower level (Norris and Inglehart 2004). The implementation of family planning policy for the past few decades accelerated the rate of decline in fertility in China. Even after the implementation of the universal two-child policy (at the beginning of 2016), low fertility rate and extended life expectancy will continue to be the primary characteristics of China's demographic situation in the future. Population aging will be the new normal in China for a long time to come. Perhaps human societies will not always experience the aging phenomenon as they are today, but with the further development of the society, economy, science, technology, 
modern medicine and many other aspects, the probability of human societies returning to a youthful state is minimal in the foreseeable future.

Since the 1950s, many countries and regions worldwide have experienced the trend of population aging. At present, more than 60 countries or regions have become aging societies; that is, societies in which the proportion of the elderly population aged 60 and over accounts for more than $10 \%$ of the total population, or the proportion of the population aged 65 and over is more than $7 \%$ of the total population. Since $2000,{ }^{1}$ China has become an aging society, and over time the proportion of elderly has increased and the speed of aging has gradually accelerated. According to the National Bureau of Statistics, the total population of people aged 60 and over reached 220 million in 2015, and the total population aged 65 and over reached 144 million. The population aged 60 and over accounts for $16.1 \%$ of China's total population, and the population aged 65 and over accounts for about $10.5 \%$ of the total population. ${ }^{2}$ The P.R.C.'s first census in 1953 showed an elderly population aged 65 and over of 26.2 million; 60 years later in 2013 that number had increased 5.5 times. Both the absolute number and growth rate of China's elderly population are well above the global average level, and this aging process will continue into the future. According to a United Nations forecast, by 2050 the absolute number of people aged $60+$ and $65+$ in China will reach 490 million and 370 million, respectively, accounting for the 36.5 and $27.6 \%$ of the whole population. During the second half of this century, China's aging process will move to a very high level, with the proportion of people aged $60+$ and $65+$ increasing to 39.6 and $33.8 \%$ of the population by $2100 .^{3}$ Therefore, the aging of society will continue to be the norm for China in the $21 \mathrm{st}$ century.

In addition to the fact that aging is accelerating, the aging trend in China has characteristics that are in some cases unique and more complex than those of other countries. The Chinese society is in a period of rapid transformation, where many aspects of the economy and society are undergoing significant changes. These include rapid urbanization and active population movements, changes in family structure and intergenerational relations, changes in demographics and in the epidemiological characteristics of disease (World Bank 2015), and the disparity between continuous expansion of the total economy and low per capita GDP. The fact that China's population aging is occurring in the midst of these other transformative changes makes the situation with respect to aging particularly complex and unsettled, and it also

\footnotetext{
1 Results of the fifth population census of China in 2000 showed the elderly population aged 65 and above had reached 88.11 million, accounting for $6.96 \%$ of the total population; the population of 60 and above had reached 130 million, accounting for $10.2 \%$ of the total population. The proportion of aging population has developed steadily during the past ten years.

2 National Bureau of Statistics of China. Statistical bulletin of national economic and social development in 2015. [EB/OL].[2016-02-29].http://www.stats.gov.cn/tjsj/zxfb/201602/t20160229_1323991.html.

3 Population Division, DESA, United Nations. Probabilistic population projections based on the World Population Prospects: The 2015 Revision[DB/OL].[2017-01-17].http://esa.un.org/unpd/ppp/.(Medium Variant).
} 
makes it more difficult for China to cope with the challenges brought by population aging.

While coping with the challenge of population aging will be a long-term priority for the Chinese government and society in the future, aging should not be misunderstood as an obstacle to national development and social progress. On the contrary, aging is a sign of social and economic development and progress ( $\mathrm{Hu}$ and Peng 2011), an irreversible trend in the development of human societies, and the new normal of Chinese society in this century.

\subsection{Re-thinking old age and the population aging is a necessity}

The aging of society is an inevitable stage in the development of human society; it is normal and neither good nor bad in and of itself. However, today many people have a fear of an aging society, because the aging of society brings with it a series of challenges and problems. The reason behind this phenomenon is that traditional socioeconomic structures and institutional arrangements are ill-equipped to respond to the changes in population age structure. We continue trying to deal with new social phenomena and new challenges to traditional ideas using policy tools and systems that are suitable for a young society. As the population structure changes, social ideas, public policy, social behavior and individual behavior also need to change. Among these, changes in our way of thinking should precede changes in public policy and social behavior. Naturally, making the aging society something people perceive as normal requires a new understanding of aging and a new attitude towards aging. This new understanding and new attitude must combine with conceptual changes to form the strategic premise for China to cope with the challenges associated with population aging.

With the acceleration of population aging on a global scale, there is growing concern about aging issues. However, there are many misunderstandings about aging, and the definition of what constitutes an elderly person is one of them. Currently, aged $60+$ or $65+$ is considered old. This standard was originally provided by the United Nations (1956; 1983). In 1956 the UN first set out the standard of old as aged $65+$, and it was intended mainly for developed countries. Then in 1982 the UN redefined the standard of old as aged 60+; the redefined standard could also be applied to developing countries, some of which were beginning to undergo societal aging. The UN standard began taking into consideration life expectancy and concerns about old-age security in the 1980s. The 1982 standard has not been revised since it was first published, and is often referred to by scholars in their discussions. In recent years, some new research on re-defining "old age" and "population aging" has emerged. Scherbov and Sanderson $(2005,2008,2010$, 2013) proposed the idea of re-measuring aging and defining being old as having 15 years of RLE (Remaining Life Expectancy) (Sanderson and Scherbov 2005, 2008, 2010). Their research results have been published in "Science" and "Nature" and other international journals. Based on a summary of historical definitions of aging, Zhai and Li (2014) built a theoretical framework that divides an individual's life cycle into three states: the "young" state, the "healthy" state and the "self-care" state. But most research about 
redefining aging in China is still quite rudimentary, focusing mainly on reviewing and combining concepts, and is often of no practical value.

\section{Evidence of the change of death probability in the elderly population}

Discussions of the elderly are based initially on the concept of life course, and death is a very important part of the course of life. The World Health Statistics report from WHO points out that mortality is a good indicator of the overall health level of a country or region. For elderly people, death probability as an index of their health condition is equally important to life expectancy. The death probability of an elderly population is closely related to the economic development, cultural and education levels, health services, and social security of the society in which that population is living. Over the past few decades, the death probability and death patterns of the elderly population in China have changed dramatically.

This paper focuses on the change of age-specific death probabilities of the elderly population since the 1980 s, and examines the gender differences, regional differences and country differences in the probability of death. This article uses the years 1982 to 2010 as the time frame because there are relatively complete demographic data available for this period. Moreover, China entered a stage of economic transition beginning in the 1980s, a period during which there have been significant changes in socioeconomic patterns and the medical and health care system, and these changes are reflected in the changes to the death level of the Chinese population. In this paper, we examine the changes to the probability of death from two perspectives: first, we examine the death probability within certain age groups across different years; and second we use the same death probability level, and then compare the age corresponding to this death level across time. This paper sets the reference points at age 60 years old and a $10 \%$ o level for death probability. This is because the traditional definition of elderly usually sets 60 years old as the beginning age at which a person is classified elderly, and the social security and retirement system and other related public policy systems also use 60 years old as a benchmark for old age. Death probability at the $10 \%$ level is normally associated with an age group that is close to old age.

In this paper, the death probabilities of the population are derived from complete life tables which are established based on data from Chinese censuses. The age-specific and gender-specific death numbers and mortality rates required to compose a life table are from the third to the sixth national censuses, which took place in 1982, 1990, 2000 and 2010, respectively; data from the national 1\% population sample surveys (a sort of mini-census occurring at the halfway point of the ten year census cycle) in 1995 and 2005 has also been used. This paper does not revise the mortality data for any of these years, but establishes complete life tables for each year by using the published mortality rates (m (x)) directly and calculates the death probabilities $(\mathrm{q}(\mathrm{x})$ ) for each age. The paper constructs complete life tables for males, females and the whole populaiton for each year. The 


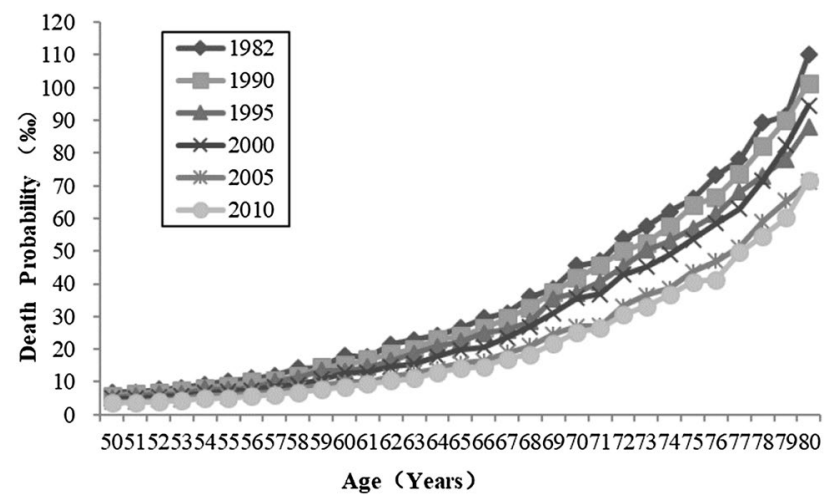

Fig. 1 Age-specific Death Probability of Chinese Population from 1982 to 2010. Sources: All values are based on life tables which were established based on data from the China Population Census and 1\% population sample survey between 1982 and 2010

quality of mortality rates in China's previous censuses (including the $1 \%$ sample surveys) varies and many scholars have published papers on the evaluation and revision of mortality data (Wang 2013; Ren and You 2004; Huang 1996; Sun et al. 1993; Zhang and Lu 1992). The different methods and assumptions that can be used to revise mortality data have different effects on the data results, but the overall trend with respect to death probability remains unchanged. This paper mainly focuses on the long-term trend of death probability changes, rather than the accuracy of specific numerical values, so while we recognise the mortality data from different censuses or sample surveys contains errors, the analysis of this paper is based on the raw mortality data. ${ }^{4}$ The data for death probability in Japan and the United Kingdom comes from The Human Mortality Database. ${ }^{5}$

\subsection{Changes of death probability by age group}

During the nearly 30 years between 1982 and 2010, the age-specific death probability curve of the Chinese population moved towards the lower right as a whole (Fig. 1, Table 1). The probability of death at the same age showed a gradual downward trend, and the age corresponding to the same death probability line gradually increased. The data shows that against a backdrop of social and economic development, progress in health care, and the improvement of people's health status, the death pattern of China's population has changed, and the probability of death at any given age has gradually decreased for China's elderly population. This result is

\footnotetext{
${ }^{4}$ We used several methods to adjust the mortality data of population censuses and $1 \%$ sampling surveys. The results showed that the general direction of the change in death probability was consistent. This paper focuses not the numerical value of death probability, but on the long-term trend of death probability changes.

5 The Human Mortality Database, http://www.mortality.org/.
} 
Table 1 Age-specific death probability of Chinese population from 1982 to 2010 $(\%)$. Sources: All values are based on life tables which were established based on data from the China Population Census and $1 \%$ population sample survey between 1982 and 2010

\begin{tabular}{|c|c|c|c|c|c|c|}
\hline Age & 1982 & 1990 & 1995 & 2000 & 2005 & 2010 \\
\hline 50 & 6.83 & 5.64 & 5.18 & 4.87 & 3.96 & 3.63 \\
\hline 51 & 6.75 & 6.40 & 5.78 & 4.86 & 3.98 & 3.75 \\
\hline 52 & 7.70 & 6.81 & 6.38 & 5.50 & 4.54 & 3.97 \\
\hline 53 & 8.26 & 7.51 & 6.38 & 5.86 & 4.81 & 4.40 \\
\hline 54 & 9.25 & 8.22 & 7.96 & 6.66 & 5.84 & 4.97 \\
\hline 55 & 10.28 & 8.94 & 7.69 & 7.20 & 5.85 & 5.17 \\
\hline 56 & 11.03 & 9.99 & 8.35 & 7.53 & 6.48 & 5.62 \\
\hline 57 & 11.92 & 10.64 & 10.08 & 8.59 & 6.75 & 6.08 \\
\hline 58 & 14.09 & 11.76 & 11.22 & 9.29 & 7.78 & 6.78 \\
\hline 59 & 14.51 & 14.54 & 13.42 & 10.75 & 8.81 & 7.64 \\
\hline 60 & 18.03 & 15.14 & 13.28 & 12.76 & 9.88 & 8.51 \\
\hline 61 & 17.54 & 16.90 & 14.45 & 12.94 & 10.07 & 9.33 \\
\hline 62 & 21.48 & 18.53 & 16.52 & 14.61 & 11.62 & 10.33 \\
\hline 63 & 22.79 & 20.12 & 18.70 & 15.44 & 12.82 & 11.06 \\
\hline 64 & 24.16 & 23.05 & 20.90 & 17.70 & 14.01 & 12.93 \\
\hline 65 & 26.53 & 23.99 & 22.32 & 19.87 & 15.78 & 14.11 \\
\hline 66 & 29.56 & 26.51 & 24.90 & 20.61 & 16.37 & 14.63 \\
\hline 67 & 30.98 & 29.49 & 25.86 & 23.48 & 18.90 & 17.08 \\
\hline 68 & 36.02 & 32.70 & 28.50 & 26.93 & 21.04 & 18.47 \\
\hline 69 & 38.52 & 37.54 & 35.42 & 31.04 & 24.52 & 21.68 \\
\hline 70 & 45.52 & 41.81 & 37.26 & 35.71 & 26.97 & 25.25 \\
\hline 71 & 46.98 & 45.70 & 40.61 & 36.94 & 27.18 & 26.38 \\
\hline 72 & 53.77 & 49.92 & 45.19 & 42.92 & 33.18 & 30.47 \\
\hline 73 & 57.50 & 52.59 & 50.38 & 45.28 & 36.54 & 33.04 \\
\hline 74 & 62.15 & 57.50 & 53.09 & 48.99 & 38.57 & 36.76 \\
\hline 75 & 66.12 & 64.08 & 57.02 & 53.63 & 43.62 & 40.67 \\
\hline 76 & 73.19 & 66.50 & 61.25 & 58.52 & 47.01 & 41.32 \\
\hline 77 & 78.01 & 73.55 & 68.11 & 63.03 & 51.17 & 49.70 \\
\hline 78 & 89.18 & 82.10 & 73.03 & 71.72 & 59.12 & 54.66 \\
\hline 79 & 91.55 & 90.12 & 78.17 & 82.38 & 65.43 & 60.25 \\
\hline 80 & 110.11 & 101.43 & 88.08 & 94.63 & 71.08 & 71.62 \\
\hline
\end{tabular}

Table 2 Death probability of 60-year-old population from 1982 to 2010 in China (\%o). Sources: All values are based on life tables which were established based on data from the China Population Census and $1 \%$ population sample survey between 1982 and 2010

\begin{tabular}{lrrrrrr}
\hline Category & 1982 & 1990 & 1995 & 2000 & 2005 & 2010 \\
\hline Overall & 18.03 & 15.14 & 13.28 & 12.76 & 9.88 & 8.51 \\
Male & 21.00 & 18.14 & 16.68 & 15.53 & 12.08 & 10.81 \\
Female & 14.97 & 11.90 & 9.78 & 9.75 & 7.56 & 6.07 \\
\hline
\end{tabular}


Table 3 The age when death probability begins to exceed 10\%o from 1982 to 2010 in China (years old). Sources: All values are based on life tables which were established based on data from the China Population Census and 1\% population sample survey between 1982 and 2010

\begin{tabular}{lllllll}
\hline Category & 1982 & 1990 & 1995 & 2000 & 2005 & 2010 \\
\hline Overall & 55 & 57 & 57 & 59 & 61 & 62 \\
Male & 54 & 55 & 56 & 57 & 59 & 60 \\
Female & 58 & 59 & 61 & 62 & 64 & 65 \\
\hline
\end{tabular}

consistent with the findings of Chen and Wang (2014), who used the mortality data of the China Health Statistics Yearbook to analyze the dynamic changes in national health, and found that the mortality rate of people over 60 years old has been declining since 1990 and the health condition of China's urban elderly and retired population has improved steadily.

Tables 2 and 3 show that in the years 1982, 1990, 1995, 2000, 2005 and 2010, the death probability of the 60 -year-old population in China was 18.03, 15.14, 13.28, $12.76,9.88$ and $8.51 \%$, respectively. The probability of death decreased by 9.52 permillage points during this near 30 year period. Before 2000, the death probability of the 60 -year-old population exceeded $10 \%$, while after 2005 , the death probability of this group began to fall below $10 \%$. The age corresponding to death probability $10 \%$ o level was 55 years old, 57 years old, 57 years old, 59 years old, 61 years old and 62 years old, respectively, in the years from 1982 to 2010 . The age gradually trended upward, showing a seven year increase during the past 30 years. Before 2000, the age corresponding to death probalility $10 \%$ o level was less than 60 years old, but after 2005 , the age corresponding to death probalility $10 \%$ o level began to be higher than 60 years old.

\subsection{Gender differences in death probability}

From 1982 to 2010, the probability of death among men of the same age was generally higher than that of women of the same age. The probability of death of the 60-year-old male population decreased from $21.00 \%$ in 1982 to $10.81 \%$ in 2010, with the probability of death dropping by 10.19 permillage points during these years. The probability of death of the 60 -year-old female population decreased from $14.97 \%$ in 1982 to $6.07 \%$ in 2010 , with the probability of death dropping by 8.9 permillage points during these years. The death probability of a 60 -year-old male remained higher than $10 \%$, while the death probability of a 60 -year-old women dropped below the $10 \%$ o level in 1995 and remained there. As for the age corresponding to death probability $10 \%$ level, the age of males rose from 54 years old in 1982 to 60 years old in 2010, while the age of women rose from 58 years old to 65 years old during the same period. For the same death probability line, women are generally older than men. Moreover, during the years 1982 to 2010, the age of men at $10 \%$ level increased by 6 years, while the age of women increased by 7 years.

Gender differences are also reflected in the rate of changes in death probability. During the past 30 years between 1982 and 2010, the death probability of the 60 -year-old population decreased by an average of 0.34 permillage points per 
Table 4 Change trends of death probability of 60-year-old population and the age when death probability begins to exceed 10\%o in China, 1982-2010 (\%o, years). Sources: All values are based on life tables which were established based on data from China Population Census and $1 \%$ population sample survey between 1982 and 2010

\begin{tabular}{|c|c|c|c|c|c|c|}
\hline \multirow[t]{2}{*}{ Category } & \multicolumn{2}{|l|}{ Overall } & \multicolumn{2}{|l|}{ Male } & \multicolumn{2}{|l|}{ Female } \\
\hline & Change range & $\begin{array}{l}\text { Annual } \\
\text { average } \\
\text { change }\end{array}$ & Change range & $\begin{array}{l}\text { Annual } \\
\text { average } \\
\text { change }\end{array}$ & Change range & $\begin{array}{l}\text { Annual } \\
\text { average } \\
\text { change }\end{array}$ \\
\hline $\begin{array}{l}\text { Death probability } \\
\text { of } 60 \text {-year-old } \\
\text { population }\end{array}$ & -9.52 & -0.34 & -10.19 & -0.36 & -8.90 & -0.32 \\
\hline $\begin{array}{l}\text { The age when } \\
\text { death prob- } \\
\text { ability begins to } \\
\text { exceed } 10 \%\end{array}$ & 7 & 0.25 & 6 & 0.21 & 7 & 0.25 \\
\hline
\end{tabular}

year, with the death probability of 60-year-old males decreasing by an average of 0.36 permillage points per year and that of women decreasing by 0.32 permillage points per year. In short, the death probability of male fell slightly faster than that of women. As for the change of the age corresponding to death probability $10 \%$ o level, the average annual increase in the age of the overall population was 0.25 years per year, with the average annual increase of males was 0.21 years and the average annual increase of females was 0.25 years (Table 4 ).

\subsection{Country difference in death probability}

Because the United Kingdom and Japan are the representative countries of the demographic transition in Western Europe and East Asia respectively, this article made a comparative analysis between the United Kingdom, Japan and China.

Compared with China during years 1980-2010, the death probability of the 60 -year-old population in the UK dropped by 8.57 permillage points during this period, with an average annual decrease of 0.29 permillage points. In China (1982-2010), the death probability of the 60-year-old population dropped by 9.52 permillage points, with an average annual decrease of 0.34 permillage points. It can be seen that during the period considered here, the death probability of the same 60-year-old age population was slightly higher in China (18.03-8.51\%o) than it was in the United Kingdom (15.61-7.04\%o), but the decline rate of death probability fell faster in China than it did in the United Kingdom. China's 60-year-old death probability in 1980 (specifically 1982) was equivalent to the level of the United Kingdom around 1945, ${ }^{6}$ while China's 60-year-old death probability in 2010 was equivalent to the level of UK in 2000. As for the age

\footnotetext{
6 According to the Human Mortality Database (http://www.mortality.org/), the death probability of the 60 -year-old population of Britain in 1945 was $18.40 \%$.
} 
Table 5 Change trends of death probability of 60-year-old population and the age when death probability begins to exceed $10 \%$ in UK, 1980-2010 (\%o, years old). Sources: The Human Mortality Database, http://www.mortality.org/

\begin{tabular}{|c|c|c|c|c|c|c|}
\hline \multirow[t]{2}{*}{ Year } & \multicolumn{3}{|c|}{$\begin{array}{l}\text { Death probability of } 60 \text {-year- } \\
\text { old population }\end{array}$} & \multicolumn{3}{|c|}{$\begin{array}{l}\text { The age when death prob- } \\
\text { ability begins to exceed } \\
10 \%\end{array}$} \\
\hline & Overall & Male & Female & Overall & Male & Female \\
\hline 1980 & 15.61 & 20.74 & 10.94 & 56 & 54 & 60 \\
\hline 1985 & 13.79 & 17.84 & 10.00 & 58 & 56 & 60 \\
\hline 1990 & 11.73 & 14.85 & 8.79 & 59 & 57 & 62 \\
\hline 1995 & 10.23 & 12.99 & 7.54 & 60 & 58 & 63 \\
\hline 2000 & 9.20 & 11.51 & 6.96 & 62 & 60 & 64 \\
\hline 2005 & 7.69 & 9.70 & 5.74 & 63 & 61 & 65 \\
\hline 2010 & 7.04 & 8.59 & 5.53 & 65 & 63 & 67 \\
\hline
\end{tabular}

\begin{tabular}{|c|c|c|c|c|c|c|}
\hline \multirow[t]{2}{*}{ Year } & \multicolumn{3}{|c|}{$\begin{array}{l}\text { Death probability of } 60 \text {-year- } \\
\text { old population }\end{array}$} & \multicolumn{3}{|c|}{$\begin{array}{l}\text { The age when death prob- } \\
\text { ability begins to exceed } \\
10 \% \text { o }\end{array}$} \\
\hline & Overall & Male & Female & Overall & Male & Female \\
\hline 1980 & 9.21 & 12.82 & 6.48 & 62 & 58 & 65 \\
\hline 1985 & 8.12 & 11.31 & 5.32 & 63 & 59 & 67 \\
\hline 1990 & 7.99 & 11.35 & 4.8 & 64 & 59 & 68 \\
\hline 1995 & 7.42 & 10.55 & 4.44 & 64 & 60 & 69 \\
\hline 2000 & 6.55 & 9.42 & 3.81 & 65 & 62 & 71 \\
\hline 2005 & 6.11 & 8.81 & 3.54 & 67 & 61 & 71 \\
\hline 2010 & 5.66 & 8.04 & 3.34 & 68 & 63 & 73 \\
\hline
\end{tabular}

Table 6 Change trends of death probability of 60-year-old population and the age when death probability begins to exceed 10\%o in Japan, 19802010 (\%o, years old). Sources: The Human Mortality Database, http://www.mortality.org/

corresponding to death probability $10 \%$ o level, in the UK the figure rose from 56 years old to 65 years old during the 30 years from 1980 to 2010 , while this benchmark age in China rose from 55 years old to 62 years old. China's age corresponding to death probability $10 \%$ o level was always lower than that in the UK during the period under consideration. There is still a certain gap in the death level of elderly population in China and that of the elderly population in the United Kingdom (Table 5).

Although Japan's aging process started earlier than China's, Japan's population transition process and life table model are very similar to China's. Therefore, the change trajectory of death probability of the elderly population in Japan can serve as an important reference point for China.

During the period 1980-2010 considered in this paper, the death probability of the 60-year-old population in Japan dropped by a total of 3.55 permillage points, with an average annual decrease of 0.12 permillage points. In comparison, during the same period, the death probability of the 60-year-old population in China (18.03-8.51\%o) was much higher than that of Japan's (9.21-5.66\%o), but the speed of decline of the death probability for this age group was faster in China 
Table 7 Change trends of death probability of 60-year-old population and the age when death probability begins to exceed 10\%o nationally, and in Shanghai and Gansu, 1982-2010 (\%o, years old). Sources: All values are based on life tables which were established based on data from the China Population Census and $1 \%$ population sample survey between 1982 and 2010. Because of the inaccessibility of data on the age-specific populations and death populations in Gansu province in 1982 and 1987, the life tables of Gansu province were for 1990 and beyond

\begin{tabular}{|c|c|c|c|c|c|c|}
\hline \multirow[t]{2}{*}{ Year } & \multicolumn{3}{|c|}{ Death probability of 60 -year-old population } & \multicolumn{3}{|c|}{$\begin{array}{l}\text { The age when death probability begins to } \\
\text { exceed } 10 \% \text { o }\end{array}$} \\
\hline & Nationwide & Shanghai & Gansu & Nationwide & Shanghai & Gansu \\
\hline 1982 & 18.03 & 11.50 & - & 55 & 59 & - \\
\hline 1987 & - & 10.66 & - & - & 60 & - \\
\hline 1990 & 15.14 & 9.17 & 16.65 & 57 & 61 & 56 \\
\hline 1995 & 13.28 & - & - & 57 & - & - \\
\hline 2000 & 12.76 & 6.45 & 15.17 & 59 & 65 & 57 \\
\hline 2005 & 9.88 & 7.27 & 10.31 & 61 & 67 & 60 \\
\hline 2010 & 8.51 & 4.43 & 9.54 & 62 & 68 & 61 \\
\hline
\end{tabular}

than in Japan. As for the age corresponding to death probability $10 \%$ o level, in Japan the age rose from 62 years old to 68 years old during the years 1980 to 2010, while in China it increased from 55 years old to 62 years old (Table 6).

Overall, the probability of death for China's elderly population is only slightly higher than that of the elderly in the United Kingdom, but much higher than that of elderly in Japan. There is still a considerable gap in the death level between elderly populations in China and those in developed countries. However, in terms of the rate of decline, death probability is dropping very rapidly in China, followed by the United Kingdom, while Japan only experienced a limited decline in death probability during the period considered in this study.

\subsection{Inter-provincial differences in death probability}

Regional development in China has been quite uneven, and regional differences in socio-economic factors have led to differences in the death probability of elderly populations in different parts of China. A comprehensive study of regional differences of death probability is beyond the scope of this paper, but the Shanghai Municipality (a provincial level entity in China) and Gansu province have been selected for in-depth analysis because they are representative of development conditions in eastern and western China, respectively. The mortality data from the provincial censuses and the $1 \%$ population sample surveys used in this paper have not been revised. Changes in death patterns among residents caused by population migration and changes to the methodology of the census over time make it very difficult to adjustment provincial mortality data. The analysis in this paper of census mortality data as originally published from Shanghai and Gansu is meant to serve as an example of regional differences in death level and death pattern changes; it is not meant to be a detailed analysis of this complex subject. 
Shanghai has China's most developed economy and the greatest proportion of elderly people of any of the regions in China. During the period considered in this paper, the death probability of Shanghai's 60-year-old population was much lower than the national average, decreasing from $11.5 \%$ in 1982 to $4.43 \%$ o in 2010 . The death probability of 60 -year-old population nationwide started to fall below $10 \%$ in 2005 , while death probability of the 60-year-old population in Shanghai has been less than $10 \%$ since 1990; Shanghai was 15 years ahead of the country as a whole (Table 7). As for the age corresponding to death probability $10 \%$ level, Shanghai's figure is 4-6 years older than the national level. During the years between 1982 and 2010, the age corresponding to death probability $10 \%$ o level in Shanghai increased from 59 years old to 68 years old, a total increase of 9 years. This increase was greater than that of the country as a whole.

Gansu province, a less developed region in western China, experienced a much slower transition of death patterns than were experienced in the more developed eastern regions of China and the country as a whole. From 1990 to 2010, the death probability of 60-year-old population in Gansu province was higher than the national average. In terms of the change rate in death probability, the death probability of the 60-year-old population in Gansu province decreased greatly, showing a total decrease of 7.11 permillage points during these 20 years. The decline rate was slightly greater than the national average during the same period. Gansu's death probability for the 60-year-old population first fell below 10\% in 2010, 5 years later than it did nationwide. As for the age corresponding to death probability $10 \%$ o level, Gansu increased from 56 years old in 1990 to 61 years old in 2010, with a total increase of 5 years. The rate of decline is roughly similar to the average level nationally, but lower than Shanghai's rate of decline.

The elderly population's death probability level and the change trends vary across different provinces in China. The above analysis suggests that with respect to the death probability level of the elderly population, Gansu lags about 20 years behind Shanghai.

Comparing Shanghai and Gansu with UK and Japan, it can be seen that the death probability of the 60-old-year population in Shanghai is higher than that in Japan, but lower than that in the United Kingdom. As for the age corresponding to death probability $10 \%$ level, the corresponding age in Shanghai is younger than that in Japan, but older than that in the UK. Gansu has both higher death probability for the elderly population and younger age corresponding to death probability $10 \%$ o level than either the UK or Japan. Overall, there is still a certain gap in death level between China and developed countries. However, if regional imbalances in China are considered, we find that some developed areas in China, such as Shanghai, have similar (or even lower) death probability levels than those found in developed countries, while other less developed regions of China lag far behind indeed. Therefore, China still has a long way to go to complete the transformation of the death patterns.

Changes in the death probability of the elderly population are affected by socioeconomic development, health patterns and other factors. As society has developed, China has experienced continuous improvements in people's productivity and living conditions, and health care and social security, as well as an increase in the average level of education. As a result, the death probability level in China has decreased 
steadily and health conditions have improved. Because the elderly population today shows different levels of death probability and health status than elderly people from previous generations, the notion of physiological age should be re-thought accordingly. When we examine elderly populations and the issues surrounding aging, it is worth re-examining whether we should continue to use 60 or 65 years old as a fixed threshold for entry into "old-age".

\section{Redefining "old-age"}

Change in the death probability level among the elderly population could serve as supporting evidence to help prove that the threshold point of entry to old-age needs to be reset.

\subsection{Old-age is a relative concept}

First of all, it should be recognized that being old is a relative concept and a stage of one's life cycle. As times have changed, there have been dramatic changes in the physiological and psychological conditions of elderly populations, their patterns of production and lifestyles, the opportunities available to them and the abilities they possess, their accumulated human and social capital, their chances to participate in economic and social development, and the environmental and technological level of the societies in which they live. People's understanding and definition of old age should change to suit the times they live in. Today's elderly are already different from elderly people in the past, and it is safe to assume that elderly populations in the future will be healthier and "younger" than their counterparts in previous cohorts. The traditional definition of old age is out of date-it needs to be re-examined. In fact, as socioeconomic development continues in the future, we can expect breakthroughs in medical and life sciences to extend the average life expectancy still further. The conditions that determine the physiological, psychological and societal age of elderly people are always in a state of flux, and we should always think of old-age as a relatively dynamic concept.

\subsection{Redefining "old-age" will influence the institutional arrangements of society}

Changing the definition of old-age is not simply a matter of changing a number, nor should it be understood in a narrow sense as a numbers game. The definition of old age directly affects the society's basic understanding of people in different age groups, and the society's arrangement of social institutions and its economic system. Redefining old-age has very important policy implications, both theoretical and practical. The definition of old-age is the foundation for studying population aging. Nowadays in almost all countries worldwide, old age is defined as beginning at a specific age and this is used as a benchmark in almost all social management systems and policies, such as the retirement system, pension policy, labor and employment policy, and the health care system. The question of where to set the boundary 
point for the beginning of old-age directly affects the current understanding of population aging and the finding of solutions to cope with challenges brought by population aging. Therefore, defining old-age correctly affects the future development of the aging society and the direction of policy design. Increasing the age at which people retire or delaying the full payment of pension benefits are not just expedient measures, but necessities brought about by rapid changes in the economic and social development of the population, especially the elderly population. Redefining old-age would allow the society to utilize the rich human capital and social capital of the elderly population, and encourage their social and economic participation. Changes in the definition of old age also directly affects the size of the elderly population, so that public policy can be designed and public resources targeted more effectively and accurately.

\subsection{Redefining "old-age" will influence the development of academic disciplines}

The definition of old age will directly influence the theoretical framework, empirical methods, academic index systems and norms of the relevant academic disciplines, thus affecting the overall development of related disciplines. This represents the academic significance of redefining old-age. The definition of old-age is key to research in several disciplines such as demography, sociology and economics. The definition of old-age determines the development of theoretical frameworks and the application of empirical methods, thus affecting the sustainable development of such disciplines. The definition of old-age affects a series of indices, such as the support ratio, societal burden coefficient, and the aging index, as well as economic growth models (that, for example, track the impact of labor resources on the economy). The accuracy with which old-age is defined directly affects the norms and stringency of academic research in related fields, and affects the theoretical and practical values used by scholars in their research. Because an accurate definition of old age is a key concern in the social sciences, the definition should be revised in a timely and dynamic fashion as needed. Such revisions should occur across different countries and regions, allowing national and historical comparisons to become new areas of discipline development. Updated standards and evaluation criteria require careful examination.

\subsection{Redefining "old-age" to promote the restructuring of the aging society in the future}

Changes in the definition of old age will help to restructure the formation of China's aging society in the future and may have a fundamental impact on China's social, economic, political and cultural development. In terms of the society, redefining old age will change the society's awareness of the elderly and aging in China. A significant number of people currently defined as elderly will no longer be classified as social burdens, social wealth consumers, social problems producers or assigned other negative roles. Instead, they should be looked at as contributors to the past and current social development and potential producers of future development, so they 
should have the right and opportunity to participate in socio-economic development and enjoy the fruits of development. The inclination to "problematize" population aging will be effectively reversed. Realizing that population aging is the inevitable result of the development of human societies will help both the society and individuals to respond actively to the challenge of population aging. Economically, the redefinition of old age will help to release and utilize the abundant human capital and social capital in the elderly population, alleviate the problem of a shrinking labor force and the drag this shrinkage puts on economic development, and ease the pressure on the pension system. Politically, redefining old-age will help to protect the political rights of the elderly population, encourage them to express their political opinions, and enhance their political status. Culturally, the re-definition of old-age will promote the traditional Chinese culture of filial piety.

Redefining old-age is a fundamental issue, as it relates to the overall situation of the aging society. Redefining old-age is necessary, important and imperative, but the complexity of this problem determines that the redefinition of old-age needs to be carefully and systematically examined over the long term.

\section{Conclusion and discussion}

China is entering an era of accelerated population aging, and not only the government, but also the society as a whole is concerned about how to deal with the challenges that come with the aging of society. Enormous amounts of resources will be invested to deal with the challenges brought by population aging. One of the keys to addressing the challenges of population aging is to change people's awareness and ideas about the elderly population and population aging. Rethinking the definition of old age is the most important starting point and foundation for this process of change. Over the past few decades, the age-specific death probability of the elderly population in China has shown a declining trend over time, indicating that the demographic situation and connotations of old-age in China have undergone major changes, giving us a strong motive to re-define old age. The elderly population is in a dynamic state of flux, so the definition of old-age should be a dynamic indicator. In addition, changes to the death probability of the elderly population in China show both gender and regional differences, as well as gaps with developed countries. It is thus essential to avoid over-simplification when re-examining the definition of old age. The overall situation of the country, as well as gender differences and regional differences all need to be taken into consideration. Globally, Europe and the United States have increased the minimum age at which one can retire and collect government pension benefits. This links a change in an individual's economically-productive life stage to changes in life expectancy. It also serves to ease pressure on pension systems, as well as to maximize the potential human capital in the elderly population to boost sustained economic growth. The gradual extension of the retirement age in China is inevitable, and the study of the definition of old age is an important basis for the making of new retirement policies. In addition, the definition of old age is related to all aspects of the aging society. If the traditional definition of old age lags 
behind the times, this can lead to a biased understanding of social issues that will affect the implementation of public policies and socio-economic development.

This article only explores the problem of redefining old age from the perspective of changes to death probability. In fact, the definition of old age is a complex systemic problem. The World Health Organization's Global Report on Aging and Health in 2015 says that "now 70 years old is not yet a 'new 60 years old"'(World Health Organization 2016). Any definition of old age must take into consideration life expectancy and healthy life expectancy, intrinsic capacity and functional ability, epidemiological changes to diseases, the diversity and fairness of health services, and other factors that influence the health and functioning of the elderly population and demographic development. We also need to further explore the question of redefining old-age from the perspectives of cognitive, physical, psychological, participation and lifestyle changes. Population aging needs to be measured by a more complex indicator system, and a theoretical framework and policy systems related to the aging society, including redefining old-age, need to be constructed.

\section{References}

Chen, X., \& Wang, P. (2014). Social change and national health dynamics in China. Chinese Journal of Population Science, 2, 63-73.

Hu, Z., \& Peng, X. (2011). China's population aging from the perspective of public policy. Social Sciences in China, 4, 106-124.

Huang, R. (1996). A comparative study of the Logit model and double-log model of population mortality. Population and Economics, 4, 9-16.

Norris, P., \& Inglehart, R. (2004). Sacred and secular: religion and polities worldwide. New York: Cambridge University Press.

Ren, Q., et al. (2004). The levels and patterns of mortality and their regional variations in China since the 1980s. Chinese Journal of Population Science, 3, 19-29.

Sun, F., Li, S., \& Li, N. (1993). A study of missing report on death in the country and some provinces based on China's fourth population census. Chinese Journal of Population Science, 2, 20-25.

United Nations. (1956). The aging of population and its economic and social implications. New York: United Nations, Series: Population studies, 7.

Sanderson, Warren C., \& Scherbov, Sergei. (2005). Average remaining lifetimes can increase as human populations age. Nature, 435, 811-813.

Sanderson, W., \& Scherbov, S. (2008). Rethinking age and aging. Population Bulletin, 63(4), 3-15.

Sanderson, W., \& Scherbov, S. (2010). Remeasuring aging. Science (Washington), 329, 1287-1288.

Sanderson, W., \& Scherbov, S. (2013). The characteristics approach to the measurement of population aging. Population and Development Review, 4, 673-685.

United Nations. (1983). The Vienna international plan of action on aging. New York: United Nations.

Wang, J. (2013). Trends in life expectancies and mortality patterns in China since 1990: a further examination and analysis. Population Research, 4, 3-18.

World Bank. (2015). Live long and prosper: aging in East Asia and Pacific. Washington, DC: World Bank.

World Health Organization. (2016). World Report on Aging and Health. [2016-11-06] http://www.who. int/ageing/publications/world-report-2015/en/.

Zhai, Z., \& Li, L. (2014). Further discussion on the standard and definition of "elderly". Population Research, 6, 57-63.

Zhang, E., \& Lu, L. (1992). An estimate of complete rate of death report of adult populatin in China's 1990 populatin census. Chinese Journal of Population Science, 3, 27-29. 

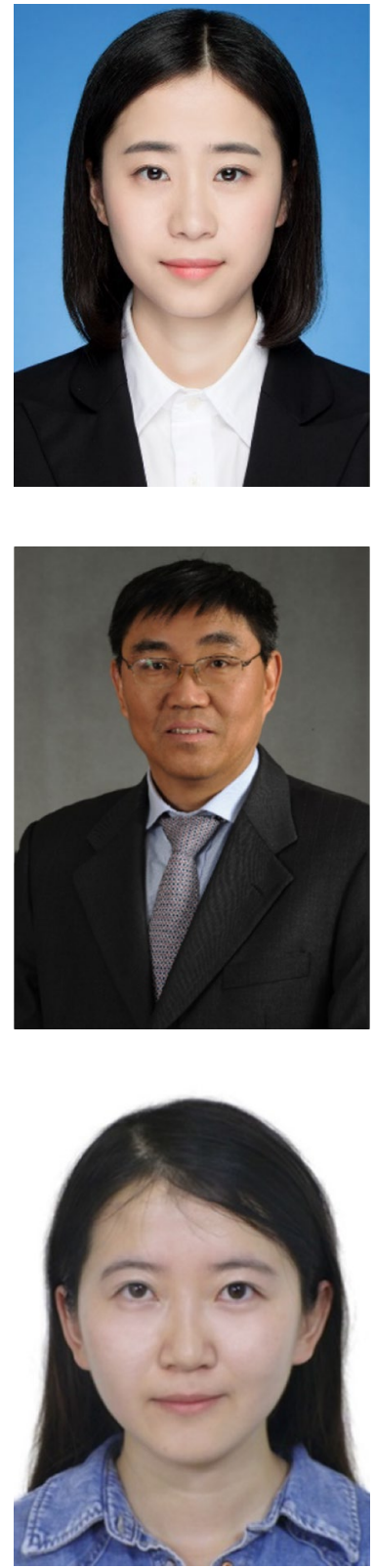

Min Lu currently a post-doctoral research fellow at the State Innovative Institute for Public Management and Public Policy Studies of Fudan University. Her academic interests are health issues of elderly population and gender development in China.
Xizhe Peng received his Ph.D. degrees in Population Studies from London School of Economics (LSE) in 1988, and has been working at Fudan University since then. He is currently professor and serves as the Director of the Research Center for Population and Development Policy Studies. His research has covered a wide range of population-related issues, including population dynamics, aging and social policy, gender and social development etc.
Mengxue Chen is currently pursuing her doctoral degree in Demography at College of Arts and Social Science of Australian National University. Her research interests include population ageing, inequality in population health (outcome and access to health services) and development studies. 